ISSN 2413-0877 Volume 3 (2016) 183-188

ICoA Conference Proceedings, 7 - 9 November 2015

\title{
Effects of Output-Input Values on Factory Productivity
}

\author{
Resa Gustanto, Suharno*, Mochammad Maksum \\ Department of Agroindustrial Technology, Faculty of Agricultural Technology \\ Universitas Gadjah Mada, Jl. Flora No.1 Bulaksumur 55281, Indonesia. \\ Email: suharno@ugm.ac.id ${ }^{*}$
}

\begin{abstract}
A sugarcane factory produces white sugar for national market. Measuring factory productivity is important to understand the factory performance. Factory productivity was measured using Multi Factor Productivity Measurement Model (MFPMM) based on an output input analysis. The results show that yearly factory productivity in the last period was lower than the previous period. The decrease of productivity was affected by decreasing company revenues and increasing input costs.
\end{abstract}

Keywords: Factory productivity; MFPMM, Multifactor; Sugarcane.

\section{INTRODUCTION}

Productivity is critical for a long-term competitiveness and profitability of organisations. The elements in the productivity cycle should always be done, namely productivity mesurement, productivity evaluation, planning productivity, and productivity improvement (Sumanth, 1984).

Multifactor productivity is defined as output per unit of combined inputs of capital, labor, energy, materials, and purchased business services. Multifactor productivity measurement model (MFPMM) is a comprehensive and analytical model for measuring productivity changes. This model is used to measure a total variation from the effects of price and productivity. Analysis is performed for both input and output in the form of more flexible. MFPMM offers a valid productivity model (Wazed and Ahmed, 2008).

Figure 1 shows that a change of company profits are affected by changes in prices, productivity, revenue, and expenses. Changes in the quantity of output affects the productivity and income. Changes in output price effect on revenue and price recovery. While the change in the quantity of inputs affect productivity and cost. Similarly, changes in unit costs have an impact on the amount of costs and price recovery.

Characteristics of MFPMM model are the revaluation, devaluation, and indexation. In essence models maintain a constant price and cost changes over time. This can be achieved by the revaluation of actual output/input prior periods as a basis for comparison of the value of other periods. Company's productivity is measured then used to determine the position of productivity to take steps to increase the productivity of the company.

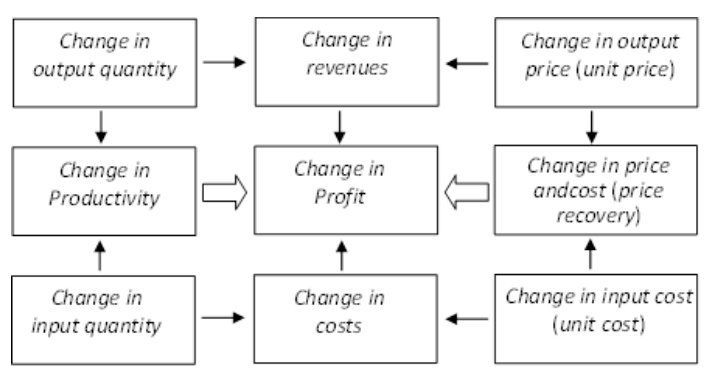

Figure 1: Nine Basic Components of MFPMM (Sink, 1985 in Phusavat, 2013)

A research study of productivity in the use of all the resources needed (inputs) to produce the desired output (output) is needed by companies who want to improve their performance and competitiveness. The measurement results can be used as an evaluation of the company's current performance and to benchmark performance improvements in the future.

\section{Research Objectives}

1) To measure factory's productivity using MFPMM model.

2) To analyse the results of productivity measurement across the study periods.

3) To develop a recommendation for factory productivity improvement. 


\section{MATERIALS AND METHODS}

\section{Outputs}

The main products of the sugar factory are: 1) white crystal sugar (SHS I Superieure hoofd suiker I), 2) molasses and 3) bagasse as a byproduct. Sugar crystals and molasses are sold as sources of income, while bagasse is not for sale but is used for fuel. Both outputs were recorded for period 1 year 2013 and period 2 year 2014 as seen on Table 1.

Output quantities of white sugar and molasses on period 2 were 311,060 quintal, and 234,405 quintal, lower than on period 1 that were 350,528 and 281,820 quintal. This decrease in quantities was also followed by a decrease on their prices. Prices of white sugar and molasses on period 2 were Rp 771,803/ton and Rp 90,909/ton, lower than on period 1 that were Rp 881,871/ton and Rp 103,953/ton.

When we see on the output side, quantity and price levels for period 2 were lower when they are compared to the period 1 output condition. The data shows that both quantity dan price levels decreased from period 1 to period 2.

Tabel 1. Factory Outputs 2013-2014

\begin{tabular}{|c|l|c|c|c|c|}
\hline \multirow{2}{*}{ Outputs } & \multicolumn{2}{|c|}{ Period 1 (2013) } & \multicolumn{2}{c|}{ Period 2 (2014) } \\
\cline { 3 - 6 } & Quantity (qu) & Price (Rp/qu) & Quantity (qu) & Price (Rp/qu) \\
\cline { 3 - 6 } & Col 1 & Col 2 & Col 4 & Col 5 \\
\hline \hline 1 & White sugar & 350,528 & 881,871 & 311,060 & 771,803 \\
\hline 2 & Molasses & 281,820 & 103,953 & 234,405 & 90,909 \\
\hline
\end{tabular}

$\mathrm{Qu}=$ quintal $=0.1 \mathrm{ton}=100 \mathrm{~kg}$

\section{Inputs}

The sugarcane factory uses three categories of inputs - labor, materials, and energy.

Labor: Table 2 shows that the numbers of labor for period 2 were lower than that of period 1 . However, the labor price of period 2 was higher than period 1. For example, number of operator decreased from 307 persons in 2013to 287 persons in 2014. However, labor prices increased from period 1 to period 2 of $\mathrm{Rp} 2,168,938$ to $\mathrm{Rp} 2,366,735$ per person per month.

Materials: Most quantities of input used for period 2 were lower compared to period 1, except the quantity of Trinatrium phosphate and Voltabio. Several prices/unit of input were also increased, some of prices were decreased.

Energy: Energy used in period 2 was lower for electricity, wood, and diesel oil, while higher use for oil Fo and tatal.

Table 2. Factory Inputs 2013-2014

\begin{tabular}{|l|r|r|r|r|}
\hline \multirow{2}{*}{ Input } & \multicolumn{2}{|c|}{ Period 1 } & \multicolumn{2}{c|}{ Period 2 } \\
\cline { 2 - 5 } & \multicolumn{1}{|c|}{ Quant. } & \multicolumn{1}{c|}{ Price/Unit } & \multicolumn{1}{c|}{ Quant. } & \multicolumn{1}{c|}{ Price/Unit } \\
\cline { 2 - 5 } & \multicolumn{1}{c|}{ Col 1 } & \multicolumn{1}{c|}{ Col 2 } & \multicolumn{1}{c|}{ Col 4 } & \multicolumn{1}{c|}{ Col 5 } \\
\hline 1. Labor & & & & \\
\hline Executives (persons) & 48 & $6,687,656$ & 46 & $6,697,615$ \\
\hline Operators (persons) & 307 & $2,168,938$ & 287 & $2,366,735$ \\
\hline Supporting (KKWT) (persons) & 1,182 & $1,515,647$ & 1,114 & $1,524,642$ \\
\hline 2. Material & & & & \\
\hline Sugarcane (qu) & $5,640,473$ & 49,500 & $5,095,211$ & 41,000 \\
\hline Lime (kg) & 706,021 & 725 & 595,544 & 820 \\
\hline Sulphur (kg) & 172,214 & 2,456 & 146,350 & 2,534 \\
\hline Superfloc (kg) & 1,891 & 45,668 & 1,718 & 68,351 \\
\hline Phospat acid (kg) & 66,570 & 9,776 & 55,790 & 12,123 \\
\hline Caustic soda (kg) & 42,158 & 6,263 & 38,146 & 6,387 \\
\hline
\end{tabular}




\begin{tabular}{|l|r|r|r|r|}
\hline Trinatrium phosphat (kg) & 16,025 & 3,223 & 16,735 & 3,708 \\
\hline Voltabio $(l)$ & 10,538 & 45,268 & 11,310 & 47,670 \\
\hline 3. Energy & & & & \\
\hline Electricity $(\mathrm{kwh})$ & $5,796,910$ & 840 & $4,694,362$ & 1,041 \\
\hline Wood $(\mathrm{kg})$ & $3,342,070$ & 372 & $2,418,860$ & 383 \\
\hline Oil Fo $(l)$ & 228,000 & 4,757 & 547,000 & 5,871 \\
\hline Tatal $(\mathrm{kg})$ & $2,649,810$ & 269 & $2,815,760$ & 280 \\
\hline Diesel fuel $(l)$ & 26,476 & 4,500 & 4,100 & 5,500 \\
\hline
\end{tabular}

\section{MFPMM Model}

The multifactor productivity measurement model (MFPMM) was originally developed in the 1970s during the APQC's initial efforts in promoting productivity measurement at an organizational and/or plant level. Since then, the MFPMM has long been implemented for assessment of corporation profitability. The essential premise for the MFPMM is that the increase in profitability is based on the improvement of two specifically areas: productivity and price recovery.

Col 1 The quantities of outputs produced and /or sold and the quantities of input consumed $\mathrm{i}$ $\mathrm{n}$ order to produce those outputs for period 1 $\left(\mathrm{Q}_{\mathrm{i} 1}\right)$. The term " $\mathrm{i}$ ” indicates the different cate gories for both the output and input.

Col 2 Representing the outputs' unit prices \& the inputs' unit cost in period $1\left(\mathrm{P}_{\mathrm{i} 1}\right)$.

Col 3 Reflecting the value (quantity unit price or unit cost) of period 1.

Col 4 Representing the quantities of outputs produced and/or sold and the quantities of input consumed in order to produce those outputs for period $2\left(\mathrm{Q}_{\mathrm{i} 2}\right)$.

Col 5 Representing the outputs' unit prices \& the inputs' unit cost in period $1\left(\mathrm{P}_{\mathrm{i} 2}\right)$.

Col 6 Reflecting the value (quantity unit price or unit cost) of period 2.

$\mathrm{Col} 6=\mathrm{Col} 4 \times \mathrm{Col} 5$

\section{Weighted Change Ratio (WCR)}

Col 7 - Price weighted and base period price indexed changes quantities (both unit price an $\mathrm{d}$ cost remained constant at period $_{1}$ ). $\frac{\sum_{i=1}^{n}\left(O_{i 2}\right)\left(P_{i 1}\right)}{\sum_{i=1}^{n}\left(O_{i 1}\right)\left(P_{i 1}\right)}$
Col 8 - Quantity-weighted and current period indexed changes unit prices and costs (both output and input quantities remained constant at period $\left._{2}\right)$.

$\frac{\sum_{i=1}^{n}\left(O_{i 2}\right)\left(P_{i 2}\right)}{\sum_{i=1}^{n}\left(O_{i 2}\right)\left(P_{i 1}\right)}$

Col 9 - Impact of changes in price and quantity from period 1 to 2 - quantity (outputs and inputs) and unit price/cost not held constant.

$\frac{\sum_{i=1}^{n}\left(O_{i 2}\right)\left(P_{i 2}\right)}{\sum_{i=1}^{n}\left(O_{i 1}\right)\left(P_{i 1}\right)}$

\section{Cost to Revenue Ratio}

Cost to revenue ratio (CRR) calculated and written at $\mathrm{Col} 10$ and $\mathrm{Col} 11$.

Col 10 - Cost to revenue for period 1 .

$\frac{I_{i j 1}}{\sum_{i=1}^{n}\left(O_{i 1}\right)\left(P_{i 1}\right)}$

Col 11 - Cost to revenue for period 2.

$\frac{I_{i j 2}}{\sum_{i=1}^{n}\left(O_{i 2}\right)\left(P_{i 2}\right)}$

\section{Productivity Ratio}

Productivity Ratio (PR) is calculated to measure output from input at certain period and written Col 12 and $\mathrm{Col} 13$.

Col 12 Output-to-input ratios for period 1.

$\frac{\sum_{i=1}^{n}\left(O_{i 1}\right)\left(P_{i 1}\right)}{\left(I_{i j 1}\right)\left(P_{i j 1}\right)}$

Col 13 Output-to-input ratios for period 2.

$\frac{\sum_{i=1}^{n}\left(O_{i 2}\right)\left(P_{i 1}\right)}{\left(I_{i j 2}\right)\left(P_{i j 1}\right)}$ 


\section{Weighted Performance Indexes}

Weighted Performance Index (WPI) is a measure of productivity when price held constant, quantity held contant, and when both price and quantity change.

Results of calculation are written at $\mathrm{Col} 14,1$ 5 , and 16.

Col 14 - Price weighted productivity indexes. $\frac{\frac{\sum_{i=1}^{n}\left(o_{i 2}\right)\left(P_{i 1}\right)}{\sum_{i=1}^{n}\left(o_{i 1}\right)\left(P_{i 1}\right)}}{\frac{\left(I_{i j 2}\right)\left(P_{i 1}\right)}{\left(I_{i j 1}\right)\left(P_{i 1}\right)}}$

Col 15 - Quantity weighted price recovery indexes.

$\frac{\frac{\sum_{i=1}^{n}\left(O_{i 2}\right)\left(P_{i 2}\right)}{\sum_{i=1}^{n}\left(O_{i 2}\right)\left(P_{i 1}\right)}}{\frac{\left(I_{i j 2}\right)\left(P_{i 2}\right)}{\left(I_{i j 2}\right)\left(P_{i 1}\right)}}$

Col 16 - Profitability indexes, reflecting the rates of change on both the quantity produced /consumed and unit price/cost.

$\frac{\frac{\sum_{i=1}^{n}\left(O_{i 2}\right)\left(P_{i 2}\right)}{\sum_{i=1}^{n}\left(O_{i 1}\right)\left(P_{i 1}\right)}}{\frac{\left(I_{i j 2}\right)\left(P_{i 2}\right)}{\left(I_{i j 1}\right)\left(P_{i 1}\right)}}$

\section{Rupiah Effect on Profit (ROP)}

Col 17 - Opportunity gain/loss from a productivity change.

$\left(I_{i j 1}\right)\left(P_{i 1}\right)\left[\frac{\sum_{i=1}^{n}\left(Q_{i 2}\right)\left(P_{i 1}\right)}{\sum_{i=1}^{n}\left(o_{i 1}\right)\left(P_{i 1}\right)}-\frac{\left(I_{i j 2}\right)\left(P_{i 1}\right)}{\left(I_{i j 1}\right)\left(P_{i 1}\right)}\right]$

Col 18 - Impact from a price recovery change. Col $18=$ Col $19-$ Col 17

Col 19 Total impact on profits from productivity/price recovery.

$\left(I_{i j 1}\right)\left(P_{i 1}\right)\left[\frac{\sum_{i=1}^{n}\left(Q_{i 2}\right)\left(P_{i 2}\right)}{\sum_{i=1}^{n}\left(o_{i 1}\right)\left(P_{i 1}\right)}-\frac{\left(I_{i j 2}\right)\left(P_{i 2}\right)}{\left(I_{i j 1}\right)\left(P_{i 1}\right)}\right]$

\section{RESULTS and DISCUSSION}

Value of outputs are obtained from the sale of products for period 1 and period 2. As shown on Tabel 3, production of white sugar during the period 1 was 350,528 quintals and sold at the price of Rp 881,871 per kg. Output from selling sugar for the period 1 was Rp 309,120,477,888 and output from selling molasses was Rp 29,296,034,460. Total output value for period 1 was $\mathrm{Rp} 338,416,512,348$. Using the same calculation method, output value for period 2 was $\mathrm{Rp}$ 261,386,565,325.

Table 3. Value of Outputs 2013-2014

\begin{tabular}{|l|c|c|c|c|c|c|}
\hline \multirow{3}{*}{ Output } & \multicolumn{4}{|c|}{ Period 1 } & \multicolumn{3}{c|}{ Period 2 } \\
\cline { 2 - 7 } & Quantity & Rp/Unit & Value (Rp) & Quantity & Rp/Unit & Value (Rp) \\
\cline { 2 - 7 } & Col 1 & Col 2 & Col 3 & Col 4 & Col 5 & Col 6 \\
\hline \hline White sugar (qu) & 350,528 & 881,871 & $309,120,477,888.00$ & 311,060 & 771,803 & $240,077,041,180.00$ \\
\hline Molasses (qu) & 281,820 & 103,953 & $29,296,034,460.00$ & 234,405 & 90,909 & $21,309,524,145.00$ \\
\hline Total Output & & & $\mathbf{3 3 8 , 4 1 6 , 5 1 2 , 3 4 8 . 0 0}$ & & & $\mathbf{2 6 1 , 3 8 6 , 5 6 5 , 3 2 5 . 0 0}$ \\
\hline
\end{tabular}

Table 4. Value of Inputs 2013-2014

\begin{tabular}{|c|c|c|c|c|c|c|}
\hline \multirow{3}{*}{ Input } & \multicolumn{3}{|c|}{ Period 1} & \multicolumn{3}{|c|}{ Period 2} \\
\hline & Quantity & Rp/Unit & Value (Rp) & Quantity & Rp/Unit & Value (Rp) \\
\hline & Col 1 & $\mathrm{Col} 2$ & Col 3 & $\mathrm{Col} 4$ & Col 5 & $\mathrm{Col} 6$ \\
\hline \multicolumn{7}{|l|}{ Labor } \\
\hline Executive (24) & 48 & $6,687,655.75$ & $7,704,179,421.43$ & 46 & $6,697,615$ & $4,611,354,108.74$ \\
\hline Operator (24) & 307 & $2,168,937.55$ & $15,980,731,865.42$ & 287 & $2,366,735$ & $10,188,795,186.24$ \\
\hline KKWT (7 month) & 1,182 & $1,515,647.28$ & $12,540,465,594.70$ & 1,114 & $1,524,642$ & $10,190,704,580.56$ \\
\hline Labor & & & $36,225,376,881.55$ & & & $24,990,853,875.54$ \\
\hline \multicolumn{7}{|l|}{ Material } \\
\hline Sugarcane (qu) & $5,640,473$ & 49,500 & $279,203,413,500$ & $5,095,211$ & 41,000 & $208,903,651,000$ \\
\hline Lime (kg) & 706,021 & 725 & $511,865,225$ & 595,544 & 820 & $488,346,080$ \\
\hline Sulphur (kg) & 172,214 & 2,456 & $422,957,584$ & 146,350 & 2,534 & $370,850,900$ \\
\hline Superfloc (kg) & 1,891 & 45,668 & $86,358,188$ & 1,718 & 68,351 & $117,427,018$ \\
\hline Phospat acid (kg) & 66,570 & 9,776 & $650,788,320$ & 55,790 & 12,123 & $676,342,170$ \\
\hline Caustic soda (kg) & 42,158 & 6,263 & $264,035,554$ & 38,146 & 6,387 & $243,638,502$ \\
\hline $\begin{array}{l}\text { Trinatrium phosphat } \\
\text { (kg) }\end{array}$ & 16,025 & 3,223 & $51,648,575$ & 16,735 & 3,708 & $62,053,380$ \\
\hline
\end{tabular}




\begin{tabular}{|l|r|r|r|r|r|r|}
\hline Voltabio (ltr) & 10,538 & 45,268 & $477,034,184$ & 11,310 & 47,670 & $539,147,700$ \\
\hline Material & & & $\mathbf{2 8 1 , 6 6 8 , 1 0 1 , 1 3 0}$ & & & $\mathbf{2 1 1 , 4 0 1 , 4 5 6 , 7 5 0}$ \\
\hline Energy & & & & & & \\
\hline Electricity (kwh) & $5,796,910$ & 840 & $4,869,404,165.53$ & $4,694,362$ & 1,041 & $4,886,830,613.87$ \\
\hline Wood (kg) & $3,342,070$ & 372 & $1,243,250,040.00$ & $2,418,860$ & 383 & $926,423,380.00$ \\
\hline Oil Fo (ltr) & 228,000 & 4,757 & $1,084,596,000.00$ & 547,000 & 5,871 & $3,211,437,000.00$ \\
\hline Tatal (kg) & $2,649,810$ & 269 & $712,798,890.00$ & $2,815,760$ & 280 & $788,412,800.00$ \\
\hline Diesel fuel (ltr) & 26,476 & 4,500 & $119,140,150.00$ & 4,100 & 5,500 & $22,550,000.00$ \\
\hline Water & & & $95,248,906.96$ & & & $85,787,324.70$ \\
\hline Energy & & & $\mathbf{8 , 1 2 4 , 4 3 8 , 1 5 2 . 4 9}$ & & & $\mathbf{9 , 9 2 1 , 4 4 1 , 1 1 8 . 5 7}$ \\
\hline $\begin{array}{l}\text { Labor + Material + } \\
\text { Energy }\end{array}$ & & $\mathbf{3 2 6 , 0 1 7 , 9 1 6 , 1 6 4 . 0 4}$ & & & $\mathbf{2 4 6 , 2 1 3 , 7 4 1 , 7 4 4 . 1 1}$ \\
\hline
\end{tabular}

\section{Weighted Change Ratio}

Calculation of Weighted Change Ratio (WCR) is intended to measure the change in quantity, price and value for period 1 and period 2. The value of change ratio indicates the level of activity from each input element to the product output.

Components of the WCR are:

(a) Change in Quantity (Col 7) obtained by dividing the product at $\mathrm{Col}$ 4 (quantity period 2) with Col 2 (price for period 1), to Col 3 (value period 1).

(b) Change in Price ( $\mathrm{Col}$ 8) obtained by dividing Col 6 (value period 2) of the product Col 4 (quantity of period 2) and $\mathrm{Col} 2$ (price period 1).

(c) Change in Value (Col 9) obtained by dividing the $\mathrm{Col} 6$ (value period 2) with $3 \mathrm{Col}$ (value period 1).

Change in quantity ( $\mathrm{Col} 7)$

$=\frac{\sum_{i=1}^{n}\left(Q_{i 2}\right)\left(P_{i 1}\right)}{\sum_{i=1}^{n}\left(Q_{i 1}\right)\left(P_{i 1}\right)}$

$=\frac{\sum_{i=1}^{n}(311.060)(\operatorname{Rp~} 881.871,00)}{(\operatorname{Rp~309.120.477.888,00)~}}=$

Change in price ( $\mathrm{Col} 8)$ :

$=\frac{\sum_{i=1}^{n}\left(Q_{i 2}\right)\left(P_{i 2}\right)}{\sum_{i=1}^{n}\left(Q_{i 2}\right)\left(P_{i 1}\right)}$

$=\frac{(\operatorname{Rp} 240.077 .041 .180,00)}{\sum_{i=1}^{n}(311.060)(\operatorname{Rp~} 881.871,00)}=0.88$

Change in value

$\operatorname{Col} 9=\frac{\sum_{i=1}^{n}\left(Q_{i 2}\right)\left(P_{i 2}\right)}{\sum_{i=1}^{n}\left(Q_{i 1}\right)\left(P_{i 1}\right)}$

$=\frac{(\operatorname{Rp~240,077,041,180.00)}}{(\operatorname{Rp~309.120.477.888,00)}}=0.78$

\section{Rupiah Effect On Profit (ROP)}

Rupiah effect on Profit (ROP) was calculated to determine the level of rupiah gains due to changes in quantity, price and value. ROP was strongly correlated to the value of Weighted Performance Index (WPI).

\section{Productivity Improvement}

The amount of sugar output SHS can be enhanced by improving the efficiency of the sugar manufacturing process. Improving employee performance with job training, provision of incentives for high performing employees. Improving material productivity by using high quality sugarcane with high sugar content.

\section{CONCLUSSIONS}

It can be be concluded that:

1. The productivity level of this sugar factory decreased slightly from period 1 (2013) to period 2 (2014).

2. Input factors that most influenced on the total productivity index was labor, materials, and energy.

3. Factory productivity may be improved by using high quality sugarcane as raw material, as well as maximizing the use of bagasse to produce electricity.

\section{REFERENCES}

Phusavat, K. 2013. Productivity Management in an Organization - Measurement and Analysis. Bangkok: ToKnow Press.

Sink, D. 1985. Productivity Management: Planning, Measurement and Evaluation, Control and Improvement. New York: Wiley. 
Sumanth, D.J. 1984. Productivity Engineering and Management. USA : McGraw Hill.

Wazed, M.A, and Ahmed, S. 2008. Multifactor Productivity Measurements Model as Effectual Performance Measures in Manufacturing. Kuala Lumpur Malaysia: Faculty of Engineering University of Malaya. 